\title{
Evaluation of breast feeding techniques among postnatal mothers and effectiveness of intervention: Experience in a tertiary care centre
}

\author{
*K Nagendra ${ }^{1}$, Pradeep Nanjappa Shetty ${ }^{1}$, Sudha Rudrappa ${ }^{1}$, Sneha Jaganath ${ }^{1}$, Reshma Nair ${ }^{1}$
}

Sri Lanka Journal of Child Health, 2017; 46: 39-43

\begin{abstract}
Background: Effective breastfeeding (BF) is a function of proper positioning and attachment of a child to mother's breast. However, there is paucity of data on mothers' skills of positioning and attachment of baby and effectiveness of educating the same in the initial days of hospital stay.
\end{abstract}

Objectives: To assess the effectiveness of educating the postnatal mothers who were feeding with incorrect positioning and attachment on the correct $\mathrm{BF}$ technique and to identify the mothers needing support and the factors affecting them.

Method: A study was done in a tertiary care hospital attached to Mysore Medical College, India, from May to September 2015. Three hundred and fifty five mothers in postnatal wards were observed when they were feeding the babies for the BF technique as per Integrated Management of Neonatal and Childhood Illnesses guideline. All mothers who performed the technique wrongly were educated about the correct technique. These mothers were assessed again at the time of discharge by the same observer.

Results: On initial observation, $67 \%$ mothers had correct positioning and $53 \%$ babies had correct attachment. However, only $43 \%$ mothers and babies had both correct positioning and attachment while BF. After the intervention, more than $97 \%$ of mothers were able to attach their babies well and $98 \%$ were able to position their babies correctly $(\mathrm{p}<0.0001)$. Infant's whole body not being well supported by mother was found to be one of the principal factors of incorrect positioning to the breast. Age, education and parity were significantly associated with mothers

${ }^{1}$ Mysore Medical College and Research Institute, Mysore, India

*Correspondence: drphoenix777@gmail.com

(Received on 03 April 2016: Accepted after revision on 20 May 2016)

The authors declare that there are no conflicts of interest

Personal funding was used in formulating the article. Open Access Article published under the Creative

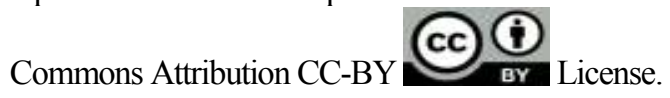

$\mathrm{BF}$ with correct technique whereas residence status of mother, mode of delivery and birth weight of baby had no significant correlation with feeding technique.

Conclusions: Educating postnatal mothers who were $\mathrm{BF}$ was found to be useful in improving the positioning and the attachment of the baby to the breast. Age, education and parity were significantly associated with mothers BF with correct technique.

DOI: http://dx.doi.org/10.4038/sljch.v46i1.8237

(Keywords: Breast feeding positioning and attachment, breast feeding practices)

\section{Introduction}

Exclusive BF is the single most effective intervention for child survival. As per Lancet 2003 series on child survival, 90\% coverage of exclusive BF from 0-6 months alone can prevent $13 \%$ of under- 5 deaths in developing countries ${ }^{1}$. A global ecological risk assessment concluded that about 1.45 million lives are lost due to suboptimal $\mathrm{BF}$ in developing countries ${ }^{2}$. WHO and UNICEF recommend initiation of BF within 1 hour and exclusive BF till 6 months of life to achieve optimal nutrition, survival, growth and development ${ }^{3}$. Globally less than $40 \%$ children less than 6 months old in the developing world are exclusively breastfed ${ }^{4,5}$.

Effective $\mathrm{BF}$ is a function of proper positioning and attachment of baby to the mother's breast. However, there is paucity of data on mothers' skills of positioning and attachment of baby in initial days of hospital stay, though community based studies are available. Majority of hospitals discharge mothers with normal delivery in 2-3 days and caesarean section mothers in 5-7 days. Since the current trend is early discharge of mothers from hospital after delivery, $\mathrm{BF}$ issues are often not addressed properly and may contribute to feeding problems, low exclusive BF rates, malnutrition and infant mortality. To the best of our knowledge, there is paucity of data from developing countries on this issue. 


\section{Objectives}

To assess the BF techniques, identify the mothers needing support and assess the effectiveness of educating them with the correct technique.

\section{Method}

This interventional study was conducted at the Cheluvamba Hospital, a tertiary care teaching hospital attached to Mysore Medical College and Research Institute, India from May to September 2015. Ethical clearance was obtained from the Ethics Committee of Mysore Medical College and Research Institute. All mothers and babies in the postnatal wards were included in the study excepting mothers with babies born at less than 34 weeks gestation, mothers with haemodynamically unstable babies and mothers with babies who had congenital anomalies. Socio-demographic characteristics were collected in a separate proforma. Age, address, education, gravida status, mode of delivery, birth weight, timing of first feeds given was noted. Informed consent was obtained from the participating mothers.

After explaining the study details, female postgraduate students observed the breast feeding technique as per Integrated Management of Neonatal and Childhood Illness (IMNCI) guidelines ${ }^{6}$. The first observation was done at around 24 hours after birth. If the mother had not fed the baby within the previous hour, she was asked to put the baby to the breast and was observed for 4 minutes. If the mother had fed her baby during the last hour, she was requested to inform when she would feed next time. Along with the 4 criteria on attachment of baby as per IMNCI, 4 criteria of positioning were also noted. Only the mothers who performed all 8 criteria correctly were considered as feeding with the right technique. All the mothers who performed any of the criteria wrongly were taken as feeding with the wrong technique. These mothers were educated about correct positioning and attachment with the aid of appropriate posters. Their mistakes were corrected and they were taught how to hold and help the baby attach properly. The mothers who were educated were assessed again by the same observer at the time of discharge, which was usually between 3 to 7 days, and positioning and attachment were noted. If there were any mistakes, they were corrected again.

\section{Outcome measures}

Primary outcome was the effectiveness of educating the postnatal mothers with the correct technique of BF i.e. the number of mothers who initially were performing any of the criteria of positioning and attachment wrongly and after education got all the criteria of positioning and attachment correct.
Secondary outcome was the number of mothers who had correct position and attachment while BF. Mothers were assigned to be feeding with correct technique only if they got right all 4 criteria of positioning and all 4 criteria of attachment. The association of age of mother, education, residence, gravida, mode of delivery and birth weight on $\mathrm{BF}$ technique were noted.

Sample size: In a study done by Thakre et al, $25 \%$ of babies had mother supporting the baby with both hands in the initial observation and $45.3 \%$ of babies had mother supporting the baby with both hands post-intervention ${ }^{6}$. With a power of $90 \%$ and an alpha-error of $5 \%$, the minimum sample size was calculated to be 195 in the intervention group. Convenience sampling technique was used.

Statistical analysis: SPSS v. 21 software was used for analysis. For interpreting pre- and post-intervention results McNemar's test was applied. To test the associations between age of mother, education, residence, parity, mode of delivery, birth weight and technique of BF, Chi-square test was used. Mean and standard deviation were used for analyzing demographic variables.

\section{Results}

Enrolment and baseline characteristics: Among the 355 mothers included in the study, mean age was $23.1 \pm 3.8$ years, mean gestational age $38.5 \pm 3.1$ weeks and mean birth weight $2.84 \pm 0.41 \mathrm{~kg}$. Whilst $43.1 \%$ of the mothers belonged to the 21-25year age group, $32.4 \%$ of mothers were less than 20 years of age. Majority $(66.5 \%)$ of the mothers were from a rural background. Only $7.3 \%$ mothers were illiterate and only $9 \%$ were working. There were almost equal numbers of primiparous (50.4\%) and multiparous $(49.6 \%)$ mothers. Whilst $71.1 \%$ of mothers had vaginal delivery, $27.5 \%$ were delivered by caesarean section and $1.4 \%$ had instrumental deliveries. Nearly one-third of babies were of low birth weight. Overall $57.5 \%$ of mothers $(67.3 \%$ of vaginal delivery mothers and $34 \%$ of caesarean section mothers) were able to initiate breast feeds within 1 hour of birth. The remaining mothers were able to initiate breast feeding within 4 hours.

Among the total 355 mothers who were assessed, the feeding technique was wrong in 206. These mothers were educated and re-assessed again. After the intervention, more than $97 \%$ of mothers were able to attach their babies well and rest of them were educated again. $98 \%$ of the mothers were able to position their babies correctly after intervention, except that $92 \%$ of mothers only were able to support 
the baby's whole body and were taught again. Preand post-intervention $\mathrm{p}$ value was significant in all the aspects of positioning and attachment $(<0.0001)$. On initial observation $67 \%$ mothers had correct positioning, 53\% babies had correct attachment, but only $42.8 \%$ of mothers had both correct positioning and attachment while feeding their babies. The remaining $57.2 \%$ were feeding with wrong technique. In positioning the baby only $32 \%$ of the mothers supported the whole body of the baby and $42.7 \%$ held the baby's neck and body straight, without bending the neck. In the attachment only $47.1 \%$ of babies had their mouth wide open and the chin was touching the breast in $55.3 \%$ of babies (Table 1 ).

Table 1: Breast feeding technique before and after intervention $(n=206)$

\begin{tabular}{|c|c|c|c|}
\hline Positioning and attachment criteria & $\begin{array}{c}\text { Before intervention } \\
\text { No. }(\%)\end{array}$ & $\begin{array}{c}\text { After intervention } \\
\text { No. }(\%)\end{array}$ & $\mathbf{p}$ \\
\hline Baby's neck and body straight (neck not bent) & $88(42.7)$ & $202(98.1)$ & $<0.0001$ \\
\hline Baby's body close to mother & $121(58.7)$ & $205(99.5)$ & $<0.0001$ \\
\hline Baby's body turned towards mother & $120(58.3)$ & $206(100)$ & $<0.0001$ \\
\hline Mother supporting baby's whole body & $66(32.0)$ & $190(92.2)$ & $<0.0001$ \\
\hline Correct positioning (all 4 correct) & $19(09.2)$ & $185(89.8)$ & $<0.0001$ \\
\hline Chin touching breast & $117(56.8)$ & $204(99.5)$ & $<0.0001$ \\
\hline Lower lip turned outward & $114(55.3)$ & $199(97.1)$ & $<0.0001$ \\
\hline Mouth wide open & $128(62.1)$ & $202(98.5)$ & $<0.0001$ \\
\hline More areola visible above than below mouth & $97(47.1)$ & $204(99.5)$ & $<0.0001$ \\
\hline Correct attachment (all 4 correct) & $64(31.1)$ & $197(96.1)$ & $<0.0001$ \\
\hline
\end{tabular}

Age, education and parity were significantly associated with mothers feeding with correct technique of feeding. However, residence status of mother, mode of delivery and birth weight of the baby did not have any significant correlation with feeding technique. (Table 2)

Table 2: Socio-demographic variables and breast feeding technique $(n=355)$

\begin{tabular}{|l|c|c|c|c|}
\hline \multicolumn{1}{|c|}{ Characteristic } & Number (\%) & \multicolumn{2}{|c|}{ Both position and attachment correct } & po-Number (\%) \\
\hline Age (years) & $115(32.4)$ & $79(68.7)$ & $36(31.3)$ & \\
20 or less & $153(43.1)$ & $72(47.1)$ & $81(52.9)$ & 0.005 \\
$21-25$ & $73(20.6)$ & $43(58.9)$ & $30(41.1)$ & \\
$26-30$ & $14(03.9)$ & $09(64.3)$ & $05(35.7)$ & \\
$31-35$ & $26(07.3)$ & $23(88.5)$ & $03(11.5)$ & \\
\hline Education & $17(04.8)$ & $10(58.8)$ & $07(41.2)$ & \\
Illiterate & $60(16.9)$ & $30(50.0)$ & $30(50.0)$ & \\
Grade 4 or less & $135(38.0)$ & $87(64.4)$ & $48(35.6)$ & \\
Grades 5-7 & $102(28.7)$ & $44(43.1)$ & $58(56.9)$ & \\
Grades 8-10 & $15(04.2)$ & $09(60.0)$ & $06(40.0)$ & \\
Grades 11-12 & & & & \\
Degree & $99(27.9)$ & $58(58.6)$ & $41(41.4)$ & \\
\hline Birth weight & $256(72.1)$ & $145(56.6)$ & $111(43.4)$ & \\
Low birth weight & & & & \\
Normal birth weight & $251(71.1)$ & $143(57.0)$ & $108(43.0)$ & \\
\hline Mode of delivery & $05(01.4)$ & $04(80.0)$ & $01(20.0)$ & \\
Vaginal & $97(27.5)$ & $55(56.7)$ & $42(43.3)$ & \\
Instrumental & & & & \\
Caesarean section & $236(66.5)$ & $130(55.1)$ & $106(44.9)$ & \\
\hline Address & $119(33.5)$ & $73(61.3)$ & $46(38.7)$ & \\
Rural & & & & \\
Urban & $175(50.4)$ & $118(67.4)$ & $57(32.6)$ & \\
\hline Gravida & $172(49.6)$ & $79(45.9)$ & $93(54.1)$ & \\
Primi & & & \\
Multi & & & \\
\hline
\end{tabular}




\section{Discussion}

Effective BF is crucial for getting all its benefits and is a function of proper positioning and attachment of child to the mother's breast. However, in our study only $42.8 \%$ of mothers had both correct positioning and attachment while feeding their babies though $67 \%$ mothers had correct position and $53 \%$ babies had correct attachment. These groups of mothers require more intensive supportive actions at the implementation of BF. Thakre et al in their study at community level found incorrect positioning in $25 \%$ to $53.8 \%$, and incorrect attachment in $26 \%$ to $58.7 \%$. In our study mothers were assigned to have correct position or attachment only if all 4 criteria were correct. However, some studies have also used different criteria, like scoring system ${ }^{8,9}$. We have also analysed mothers who had both position and attachment correct, which is lacking in most of the studies.

In our study on positioning, the most common mistake was that only $32 \%$ of mothers were supporting the whole body of the baby followed by $42.7 \%$ keeping the baby's body straight; $58.7 \%$ mothers kept the baby's body close to their body and baby's body was turned towards mother in 58.3\%. Infant's whole body not being well supported by mother was found to be one of the principal reasons for incorrect positioning to the breast. Thakre et al and Gupta et al also had similar findings with only $25 \%$ and $12.9 \%$ supporting the whole body of the baby respectively ${ }^{5,9}$.

In attachment, the most common mistake was that only $47.1 \%$ was latching with upper areola more visible than lower areola. In our group, $55.3 \%$ of babies were keeping the lower lip everted, in $56.8 \%$ babies the chin was touching the breast and $62.1 \%$ babies kept their mouth wide open. These findings were similar to the study by Thakre et al, with only $26.9 \%$ of observations having upper areola more visible than lower areola as the most prevalent mistake in attachment ${ }^{7}$.

After intervention a significant number $(\mathrm{p}<0.0001)$ of mothers got their positioning right, but still 7.8\% were not fully supporting the baby's body and required to be educated again. However significant number of babies $(p<0.0001)$ were well attached to their mother.

In our study maternal age, education and parity were significantly associated with mothers feeding with correct technique of feeding, whereas residence status of mother, mode of delivery and birth weight of the baby did not have any significant correlation with feeding technique. Similar findings are shown by Gupta et al, Rahim et al and Goyal et al where there was poorer positioning and attachment among primipara than multipara mothers ${ }^{7,8,10}$. Goyal et al also found no significant association with mother's age or birth weight of baby with positioning and attachment ${ }^{10}$.

Studies have shown caesarean delivery as an independent risk factor for breastfeeding problems ${ }^{11}$. Maternal pain, fear and stress, fatigue, and prolonged recovery affects breast feeding in caesarean delivery. However in our study there was no significant association with mode of delivery. In this study, after intervention mothers and babies were followed up till they were discharged from the hospital, which varied from 3 to 7 days. Further studies with long term follow up to assess the effect of in hospital education on sustenance of correct BF techniques, BF problems and exclusivity are needed.

\section{Conclusions}

Educating postnatal mothers who were BF was found to be useful in improving the positioning and the attachment of the baby to the breast. Age, education and parity were significantly associated with mothers $\mathrm{BF}$ with the correct technique.

\section{Acknowledgements}

The authors extend their acknowledgement to all the mothers and neonates who participated in the study.

\section{References}

1. Darmstadt GL, Bhutta ZA, Cousens S, Adam $\mathrm{T}$, Walker $\mathrm{N}$, de Bernis $\mathrm{L}$, et al. Evidence-based, cost-effective interventions: how many newborn babies can we save? Lancet 2005 ; 365(9463): 977 88.

2. Lauer JA, Betrán AP, Barros AJ, de Onís M. Deaths and years of life lost due to suboptimal breast-feeding among children in the developing world: a global ecological risk assessment. Public Health Nutrition 2006; 9(6): 673-85.

3. Infant and young child feeding Model Chapter for textbooks for medical students and allied health professionals. World Health Organization. 2009. Available from 
http://whqlibdoc.who.int/publications/2009/ 9789241597494_eng.pdf (Accessed on 10 February, 2016).

4. UNICEF. Nutrition. Available from http://www.unicef.org/nutrition/index_2482 4.html (Accessed on 10 February, 2016).

5. World Health Organisation.10 facts on breast feeding. Available from: http://www.who.int/features/factfiles/breastf eeding/en/ (Accessed on 10 February, 2016).

6. Ramji S. Integrated management of neonatal and childhood illness (IMNCI): implementation challenges in India. Indian Pediatrics 2006; 43(12): 1029-31.

7. Thakre SB, Thakre SS, Ughade SM, Golawar S, Thakre AD, Kale P. The Breast feeding Practices: The positioning and attachment initiative among the mothers of rural Nagpur. Journal of Clinical and Diagnostic Research 2012; 6(7): 1215-8.

8. Rahim F, Muhammad J, Ali S, Amir S. Breastfeeding practices in neonatal units. Journal of Medical Science 2014; 22(4): $159-63$.
9. Gupta M, Aggarwal AK. Feasibility study of IMNCI guidelines on effective breast feeding in a rural area of North India. Indian Journal of Community Medicine 2008; 33(3):201-3.

10. Goyal RC, Banginwar AS, Ziyo F, Toweir AA. Breast feeding practices: Positioning, attachment (latch-on) and effective sucklingA hospital-based study in Libya. Journal of Family and Community Medicine 2011; 18:74-9.

11. Suresh S, Sharma KK, Saksena M, Thukral A, Agarwal R, Vatsa M. Predictors of breast feeding problems in the first postnatal week and its effect on exclusive breastfeeding rate at six months: experience in a tertiary care centre in Northern India. Indian Journal of Public Health. 2014; 58(4):270-3. 